\title{
Anotações Sobre a Psicologia Jurídica
}

Notes On Forensic Psychology

Anotaciones sobre la Psicología Forense

Leila Maria Torraca de Brito

Universidade do Estado do Rio de Janeiro

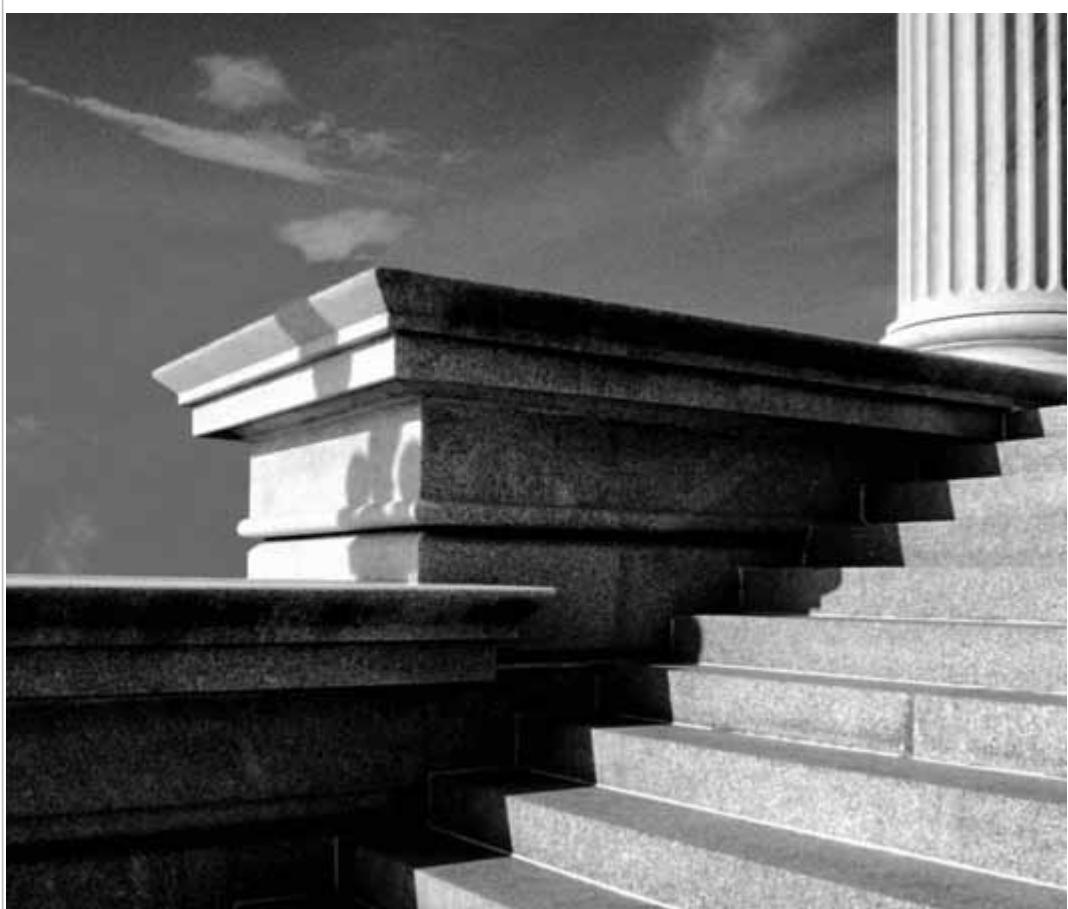


Resumo: O artigo traz considerações sobre a denominada Psicologia jurídica, área que, na atualidade, vem gerando discussões em torno das distintas demandas que lhe são direcionadas. Visando a situar a Psicologia jurídica na conjuntura dos cinquenta anos da profissão no Brasil, apresentam-se breves trechos de sua história no âmbito nacional, algumas práticas desenvolvidas inicialmente por profissionais que optaram por atuar nesse campo e as discussões que essas práticas suscitaram na seara do Direito da infância e da juventude, do Direito de família e da execução penal. Por fim, discorre-se sobre o contexto que se descortina para a Psicologia jurídica no terceiro milênio, apontando-se as tensões e as complexidades que persistem. Concluise pela necessidade de uma postura de investigação ou de desconfiança, por parte dos psicólogos, não em relação aos seus clientes, mas no que diz respeito às solicitações que lhes são encaminhadas, para que assim possam construir, com ética, caminhos e práticas profissionais.

Palavras-chave: Psicologia jurídica. Processos legais. Problemas sociais. Atuação do psicólogo.

Abstract: The paper presents considerations about the so-called forensic psychology, area that at present is generating discussions about the different demands directed to them. In order to situate the forensic psychology at the juncture of the fiftieth anniversary of the profession in Brasil, the paper provides brief excerpts of its story at the national level, some practices originally developed by professionals who have chosen to work in this field and discussions that have been raised in the area of law of children and youth, in family law and in criminal enforcement. Finally, it discusses the context that leads to forensic psychology in the third millennium, pointing out the tensions and complexities that persist. It concludes by the need for a research position, or of mistrust among psychologists not vis-à-vis their customers, but in respect of which requests are forwarded, so they can build, with ethics, their paths and their professional practices.

Keywords: Forensic psychology. Legal processes. Social issues. Psychologist performance.

Resumen: El artículo trae consideraciones sobre la denominada Psicología jurídica, área que, en la actualidad, viene generando discusiones en torno de las distintas demandas que le son direccionadas. Visando situar la Psicología jurídica en la coyuntura de los cincuenta años de la profesión en el Brasil, se presentan breves trechos de su historia en el ámbito nacional, algunas prácticas desarrol1adas inicialmente por profesionales que optaron por actuar en ese campo y las discusiones que esas prácticas suscitaron en el ámbito del Derecho de la infancia y de la juventud, del Derecho de familia y de la ejecución penal. Por fin, se discurre sobre el contexto que se descortina para la Psicología jurídica en el tercer milenio, apuntándose las tensiones y las complejidades que persisten. Se concluye por la necesidad de una postura de investigación o de desconfianza, por parte de los psicólogos, no en relación a sus clientes, sino en lo que dice respecto a las solicitudes que les son encaminadas, para que así puedan construir, con ética, caminos y prácticas profesionales.

Palabras clave: Psicología forense. Procesos legales. Problemas sociales. Actuación del psicólogo.

Ao avaliar os cinquenta anos da profissão de psicólogo no Brasil e os rumos que seguiram as diferentes áreas da Psicologia, não se poderia deixar de incluir algumas considerações sobre a denominada Psicologia jurídica, área que, na atualidade, vem motivando discussões em torno das distintas demandas que lhe são direcionadas. No presente artigo, portanto, pretende-se descrever alguns percursos históricos além dos caminhos teórico-práticos percorridos nessas cinco últimas décadas por essa que é vista, no presente, como mais uma especialidade da Psicologia.

\section{Trechos que circundam a história da Psicologia jurídica}

Embora alguns possam supor que a Psicologia possibilidade de trabalho para os psicólogos, certos autores esclarecem (Anastasi, 1972) que, no contexto internacional, foram as demandas provenientes do Poder Judiciário que ajudaram a Psicologia a se firmar como ciência. No final do século XIX, as solicitações para que se realizassem pesquisas que indicassem parâmetros para aferir a fidedignidade, ou não, dos testemunhos prestados na Justiça foram, para alguns, responsáveis pelo surgimento dos chamados laboratórios de Psicologia experimental, onde se desenvolveram estudos sobre memória, sensação e percepção, dentre outros temas pertinentes ao estudo do testemunho, como explica Brito (1993).

Como se sabe, a criação da Psicologia como ciência está diretamente relacionada à 
fundação, por Wundt, do primeiro laboratório de Psicologia experimental, que ocorreu em 1879, em Leipzig, Alemanha, e que serviu de modelo para outros laboratórios em distintos países. A visão positivista de ciência que vigorava na época incluía os experimentos realizados em laboratórios bem como o uso de métodos que se supunha semelhantes aos empregados pelas chamadas ciências da natureza.

No Brasil, a regulamentação do exercício profissional da Psicologia ocorreu em 1962, não sendo por acaso que as grades curriculares dos cursos superiores que surgiam no século passado seguissem esse mesmo viés positivista. Krüger (2009), ao narrar detalhes a respeito da criação, em meados dos anos 60, do Curso de Psicologia da então denominada Universidade do Estado da Guanabara (UEG), hoje Universidade do Estado do Rio de Janeiro (UERJ), lembra que uma das exigências do concurso de habilitação ao referido curso versava sobre conhecimentos de matemática, na medida em que os alunos deveriam cursar diversas disciplinas relacionadas à estatística, matéria fundamental ao estudo da psicometria.

Nesse mesmo rumo sobre o que era considerado científico, seguia a Psicologia jurídica. Mira y López, em sua conhecida obra denominada Manual de Psicologia Jurídica, já advertia, ao abordar no início do livro o "estado atual da Psicologia como ciência", que a Psicologia "é uma ciência que, pelo menos, oferece as mesmas garantias de seriedade e eficiência que as restantes disciplinas biológicas" (1945/1967, p. 7). Os dados matematicamente comprováveis, aferidos por meio de testes e traduzidos em percentis, também são exaltados na publicação desse autor, junto aos critérios de objetividade e de neutralidade científica que deveriam nortear trabalhos e pesquisas. Provas ou técnicas para aferir e obter a máxima sinceridade dos testemunhos, bem como para determinar a periculosidade dos delinquentes, encontram-se descritas em diversos trechos dedicados ao tema no livro, que apresenta a Psicologia do testemunho como "um dos capítulos mais brilhantes da Psicologia jurídica" (1945/1967, p. 159).

Ao mencionar o trabalho e a dedicação de Mira y López (1896-1964), já naquela época, à área da Psicologia jurídica, não se pode desconsiderar o legado deixado por esse psiquiatra espanhol, que, como comenta Jacó-Vilela (1999a), veio ao Brasil em 1945 para ministrar cursos, retornando em 1947, a convite, para criar o Instituto de Seleção e Orientação Profissional (ISOP), da Fundação Getúlio Vargas.

No livro em que Mira y López se dedica ao estudo da Psicologia jurídica, evidencia-se uma estreita relação desta com o Direito penal, ligação que, segundo Jacó-Vilela (1999b), foi responsável pelo interesse de Eliezer Schneider (1916-1998) pela área. Considerado também um dos pioneiros dessa matéria no Brasil, esse ilustre professor esteve à frente da disciplina eletiva Psicologia jurídica, tanto no início do curso de Psicologia oferecido pela Universidade do Estado do Rio de Janeiro como no curso da Universidade Federal do mesmo Estado. Aliás, segundo informa a citada autora, esse pesquisador sempre procurou inserir a disciplina na grade curricular dos cursos de Psicologia nos quais lecionava. Advogado por formação, Schneider não chegou a exercer a profissão, todavia, seus estudos sobre o Direito - especialmente o Direito penal - despertaram seu interesse pela Psicologia.

A personalidade do criminoso, o papel da punição, a influência do sistema penal na recuperação, ou não, da delinquência, esses são os temas de seu interesse. Não a formalidade da lei, mas seus efeitos na constituição do indivíduo (1999b, p.332) 
Foi na UERJ, porém, que esse professor, em 1971, assumiu o cargo de diretor do então Instituto de Psicologia e Comunição Social, quando o curso de Psicologia foi desmembrado do Instituto de Biologia (Krüger, 2009). Como se pode recordar, essa aproximação com as ciências biológicas creditava um caráter científico à Psicologia. Naquela mesma universidade, em 1986, teve início a primeira turma do Curso de Especialização em Psicologia Jurídica, projeto que contou com a fundamental participação de Schneider. O curso em questão, desde aquela época, mantém-se como uma referência na área.

\section{Apontamentos sobre as práticas iniciais}

No Brasil, os primeiros trabalhos realizados por psicólogos junto ao Judiciário seguiram o caminho anteriormente trilhado pelos médicos na elaboração de perícias. Com diagnósticos no campo da psicopatologia, cabia ao profissional fornecer um parecer técnico-científico visando a fundamentar as decisões dos magistrados. Nesse sentido, esses psicólogos não eram servidores do Judiciário, mas profissionais indicados como peritos pelos magistrados, visando à realização de diagnósticos psicológicos.

Nos anos 80, tem-se notícia da criação do cargo de psicólogo junto ao Poder Judiciário do Estado de São Paulo. Como aponta Bernardi,

Em 1985, ocorreu o primeiro concurso público para a capital de São Paulo, com a criação de 65 cargos efetivos e 16 cargos de chefia (...). O provimento de lei CCXXXVI, do Conselho Superior de Magistratura, regulamentou a atuação dos psicólogos do Tribunal de Justiça, disciplinando as funções nas Varas de Menores e nas Varas de Família e Sucessões cumulativamente (1999, p.107)
Nesse mesmo Estado, prossegue Bernardi, em 1993, houve a eleição e a posse da primeira diretoria da Associação dos Assistentes Sociais e Psicólogos do Tribunal de Justiça do Estado de São Paulo (AASPTJ-SP), associação que continua representando os interesses dessas categorias junto ao tribunal paulista.

Em Minas Gerais, o primeiro concurso para o cargo junto ao Tribunal de Justiça ocorreu em 1992 (Barros, 2001), sendo que, no Estado do Rio de Janeiro, só em 1998 foi efetuado o certame (Coimbra, 2002). Antes disso, porém, diversos psicólogos já atuavam no Judiciário carioca, existindo, inclusive, os chamados Setores de Psicologia, principalmente nas Varas da Infância e da Juventude. Nesses setores, os profissionais ou eram cedidos por outras instituições ou se encontravam no chamado desvio de função. Teixeira e Belém, ao abordarem o surgimento do Núcleo de Psicologia do Juizado da Infância e da Juventude do Rio de Janeiro, afirmam que essa foi iniciativa individual de um juiz, que criou o referido núcleo em 1992, e para onde foram designadas oito psicólogas, "chegando posteriormente a um total de dezenove na composição da equipe" (1999, p.60). Todavia, é possível recordar que, nesse mesmo Juízo, no final dos anos 70, ou seja, na vigência do Código de Menores de 1927 e, posteriormente, do Código de Menores de 1979, havia o denominado Serviço de Liberdade Assistida (SLA), composto por psicólogos voluntários e por aqueles cedidos por outras instituições.

Nesse sentido, não causam surpresa as reivindicações para a criação do cargo que passaram a ocorrer durante eventos da área realizados nas últimas décadas do século XX. No encontro Psicologia e Instituições de Direito: a Prática em Questão, Mures, representando o Conselho Regional de Psicologia-RJ, afirmava que "os profissionais de Psicologia na Justiça, enquanto cargo, estão na clandestinidade. Mas, enquanto função, 
têm um trabalho efetivo e uma contribuição técnica e científica presente e reconhecida" (p. 59). Já Teixeira (1993), então diretora do Sindicato dos Servidores do Poder Judiciário do Rio de Janeiro, reconhecia que a luta para se estabelecer o cargo junto ao Judiciário na época era recente, despontando a partir da vigência do Estatuto de Criança e do Adolescente.

Nos idos de 1990, percebe-se que as discussões abarcavam não só as possibilidades de criação de vagas para o cargo de psicólogo junto ao Judiciário como também incluíam a atuação profissional, que, para muitos, como Miranda Júnior (1998), Bernardi (1999) e Brito (1993), dentre tantos outros autores, não deveria ser reduzida à realização de perícias. Esse mesmo debate foi evidenciado em diversos eventos acadêmicos, não podendo ficar de fora, certamente, do contexto que envolveu o III Congresso Iberoamericano de Psicologia Jurídica, realizado em São Paulo, em 1999. Naquele evento acadêmico, Saunier questionava

¿Y cuál es en este entramado el posible lugar del psicólogo?; ¿y cuál su función? Resulta claro que el mayor de los riesgos para el psicólogo es el de establecerse como 'auxiliar' sustentando un discurso jurídico que lo asimila y lo borra con el solo fin de dictaminar lo 'verdadero' (1999, p.324)

Cabe recordar, ainda, que, no sistema penal brasileiro, já existiam psicólogos atuando nos anos 90, mormente após o advento da Lei de Execução Penal de 1984 (Lei no 7.210/84), que dispôs sobre a Comissão Técnica de Classificação que deveria existir em cada estabelecimento penal. Como se lê no artigo 70 da referida legislação:

Art. 7o - A Comissão Técnica de Classificação, existente em cada estabelecimento, será presidida pelo diretor e composta, no mínimo, por dois chefes de serviço, um psiquiatra, um psicólogo e um assistente social, quando se tratar de condenado à pena privativa da liberdade.

Quanto às atribuições dessa comissão, o artigo 60 da mesma lei dispunha:

Art. 60 A classificação será feita por Comissão Técnica de Classificação, que elaborará o programa individualizador e acompanhará a execução das penas privativas de liberdade e restritivas de direitos, devendo propor, à autoridade competente, as progressões e regressões dos regimes, bem como as conversões.

Tais incumbências já sofriam críticas naquela época, pois muitos psicólogos alegavam que não seria de competência da categoria propor regressões ou progressões de regime para os detentos. Além disso, os critérios que norteavam tais avaliações -quase sempre centrados no grau de periculosidade que o preso ainda apresentasse -também eram motivo de contundentes reprovações, como expôs Rauter:

A defesa e a manutenção da ordem institucional é o princípio a partir do qual é interpretado o comportamento do preso, na situação do exame. As tentativas de oposição, as manifestações de indisciplina são vistas como indícios de não recuperação ou de distúrbio mental. A colaboração, o respeito às normas e à hierarquia institucional, sim, constituem sinais de normalidade e regeneração (1989, p.17)

No campo da Justiça da infância e da juventude, apesar de o Código de Menores de 1979 (Lei no 6.697/1979) fazer referência às equipes que deveriam ser compostas por pessoal técnico, foi o Estatuto da Criança e do Adolescente (Lei no 8069/1990) que, de forma incisiva, trouxe, pelo seu artigo 150, a necessidade de previsão de recursos para a manutenção de equipe interprofissional para assessorar os juízos. Todavia, à semelhança do mencionado a respeito do sistema prisional, pesquisas desenvolvidas na vigência do Código de Menores de 1979 já sinalizavam certa inadequação dos trabalhos realizados 
nas Fundações Estaduais de Bem-Estar do Menor (FEBEM) de algumas localidades. Os laudos confeccionados sobre os internos também eram motivo de severas críticas devido, notadamente, aos critérios utilizados para aferir a reabilitação, ou não, dos que se encontravam institucionalizados. Violante, ao se referir à pesquisa empreendida na FEBEM de São Paulo, nomeou as normas vigentes na instituição de "estratégias de adestramento" (1984, p. 96), mostrando que a reabilitação dos internos era avaliada a partir do que se considerava como a "incorporação adequada do sistema educacional" (1984, p.106) de cada unidade de internação. A autora não percebia qualquer questionamento, por parte da equipe, a respeito do que estava sendo oferecido a esses jovens ou sobre as condições em que se dava essa internação.

Na seara do Direito de família, inicialmente, as atividades dos psicólogos dividiam-se entre as demandas para atuação como perito ou como assistente técnico, sem vínculo empregatício com o Poder Judiciário. Como relatam Ramos e Shaine (1994), o primeiro concurso para o cargo de psicólogo do Tribunal de Justiça de São Paulo visava ao trabalho na Vara da Infância e da Juventude, sendo, eventualmente, estendido às Varas de Família. Anos mais tarde é que foram organizados os núcleos que passaram a assessorar essas últimas Varas.

\section{O contexto da Psicologia jurídica nacional no terceiro milênio}

Atualmente, após os Tribunais de Justiça de vários Estados brasileiros terem criado o cargo de psicólogo, havendo diversos profissionais que atuam principalmente com questões relacionadas ao Direito da infância e da juventude e ao Direito de família, o Conselho Federal de Psicologia (CFP) tem dedicado especial atenção a essa área. A justa preocupação do CFP com os rumos dos trabalhos desenvolvidos deriva, também, do grande número de representações - junto às comissões de ética dos Conselhos Regionais de Psicologia - contra psicólogos que executam trabalhos direcionados ao sistema de Justiça (Conte, 2006). Tal fato certamente contribuiu para que, nos últimos tempos, esse Conselho de classe realizasse diversos eventos sobre os temas afetos a esse campo bem como organizasse diversas publicações.

Destaca-se, contudo, que o CFP vem usando a designação psicologia na interface com a Justiça, a partir do entendimento de que essa expressão incluiria não só os profissionais lotados nos tribunais mas também os que executam trabalhos que são encaminhados ao sistema de Justiça, ou seja, psicólogos que não possuem vínculo empregatício com o Poder Judiciário. Inserem-se aí, portanto, trabalhos realizados por aqueles que atuam em consultórios clínicos e os que compõem equipes de outras instituições, convidados ou solicitados a emitir pareceres que serão anexados aos autos processuais. Nesse último grupo, pode-se listar, por exemplo, os psicólogos que exercem sua prática profissional em unidades que executam medidas socioeducativas, em penitenciárias, em Conselhos Tutelares, em CREAS e em ONGs, entre outros. Tais explicações também se encontram presentes em algumas indicações para atuação de profissionais, elaboradas pelo Centro de Referência Técnica em Psicologia e Políticas Públicas (Crepop), como as dispostas nas Referências Técnicas para Atuação do Psicólogo em Varas de Família (2010).

Apesar da atual compreensão sobre a abrangência desse campo e do considerável número de profissionais que nele atuam, muitas vezes se percebe que o psicólogo jurídico, ao iniciar seu trabalho, não dispõe de conhecimentos acerca das peculiaridades que envolvem essa prática junto ao sistema 
de Justiça, além de não possuir muita noção de suas reais atribuições. Nesse contexto de trabalho, os profissionais são chamados a responder a problemáticas que Ihes parecem, e na verdade o são, inéditas. Em meio aos processos em que constam as designações para atuação do profissional, ou de membro da equipe de Psicologia, despontam expressões e termos por vezes desconhecidos dos psicólogos, alheios a sua bagagem teórica, fato que requer, portanto, amplo questionamento a respeito do que Ihes cabe realizar. Nessa teia de vocábulos e argumentações próprias de outra área de conhecimento, cabe ao psicólogo delimitar, discernir qual a temática que lhe diz respeito, evitando apropriar-se da demanda que lhe chega a partir de nomenclaturas diversas. Entende-se que o profissional não deve se ater à tipificação legal do caso, mas procurar identificar, no âmbito dos estudos empreendidos pelas ciências humanas, com quais temas pode contribuir. As inúmeras possibilidades que levam o profissional a encaminhar os resultados de seus trabalhos ao sistema de Justiça apontam, inicialmente, a importância de o psicólogo ter clareza do papel que está desempenhando em cada contexto. Seria o de assistente técnico de uma das partes do processo? Um perito designado pelo juízo? Psicólogo de equipe interdisciplinar de alguma instituição? Seria o de terapeuta daquele paciente? Como argumenta Urra Portillo: "un verdadero problema se genera cuando se confunden los papeles de terapeuta y perito (...) (2010, p. 96)." Cabe ressaltar, assim, que é a partir do claro entendimento da incumbência que Ihe cabe que o psicólogo poderá ter ciência dos limites e dos propósitos de sua atuação, transmitindo também tais informações a seu cliente. Pode-se recordar que o Código de Ética dos Psicólogos (2005, p.8) indica, na alínea $\mathrm{f}$ do artigo $1^{\circ}$, que se deve fornecer ao cliente "informações concernentes ao trabalho a ser realizado e ao seu objetivo profissional".
Destaca-se, todavia, que, apesar de atualmente alguns Tribunais do País alocarem psicólogos que integram seus quadros na função de analista judiciário, esse fato não os exime da obrigação de seguir os preceitos éticos da categoria profissional. Mesmo sob o enquadre funcional de analista judiciário, os profissionais continuam respondendo, atuando e assinando documentos como psicólogos, além de integrarem serviços de Psicologia. Nesses casos, sempre que o profissional estiver desenvolvendo trabalhos nessa qualidade, é mister seguir o código de ética da sua profissão. Dessa forma, não há motivo para supor que, junto ao sistema de Justiça, o psicólogo estaria desobrigado de manter o sigilo profissional. Nessas situações, cabe recordar que o Código dispõe, na alínea b do artigo $6^{0}$, que o psicólogo, no relacionamento com profissionais de outras áreas de conhecimento, "compartilhará somente informações relevantes para qualificar o serviço prestado, resguardando o caráter confidencial das comunicações, assinalando a responsabilidade, de quem as receber, de preservar o sigilo" (2005, p.12).

No que se refere às formas de intervenção, certamente devem estar de acordo com os estudos e as práticas reconhecidas pela Psicologia, como indica, por exemplo, a Resolução n 007/2003, do CFP, que institui o Manual de Elaboração de Documentos Escritos. Nesse sentido, não se pode deixar de mencionar que a confecção de pareceres nessa área também vem sendo intensamente debatida, havendo recomendação de que os profissionais, na elaboração de tais documentos,

\footnotetext{
devem se basear exclusivamente nos instrumentais técnicos (entrevistas, testes, observações, dinâmicas de grupo, escuta, intervenções verbais) que se configuram como métodos e técnicas psicológicas para a coleta de dados, estudos e interpretações de informações a respeito da pessoa ou grupo atendidos (...) (Resolução CFP nº 007/2003, p.4)
} 
Para melhor compreensão da complexidade que envolve uma avaliação psicológica, tarefa constantemente demandada àqueles que executam trabalhos direcionados ao sistema de Justiça, considera-se que não se deve desmembrar essa expressão, reduzindo-a a uma investigação qualquer, sob o risco de se deixar de lado toda a riqueza e a especificidade que contempla. Equiparar o termo avaliação psicológica ao ato de investigar pode conduzir ao uso de procedimentos que parecem se afastar do domínio das técnicas psicológicas, aproximando o trabalho que se produz na área da Justiça ao de uma investigação de outra natureza, com instrumentos que seriam alheios à Psicologia. Dessa maneira, comportamentos como suspeitar de quem se está atendendo, verificar se o que está sendo dito seria verídico ou não e desenvolver uma postura investigativa soam como tarefas apropriadas a outras categorias profissionais que não a dos psicólogos. Retornando a Resolução $n^{\circ}$ 007/2003, pode-se recordar que nesta se encontra a definição de que

o processo de avaliação psicológica deve considerar que os objetos desse procedimento (as questões de ordem psicológica) têm determinações históricas, sociais, econômicas e políticas, sendo as mesmas elementos constitutivos no processo de subjetivação (2003, p.4)

Quanto às conclusões do trabalho expostas nos documentos escritos, devem estar baseadas em referencial técnico e teórico apropriado à Psicologia, o que afasta os psicólogos que atuam na interface com a Justiça da incumbência de redigir sentenças ou de indicar medidas judiciais. Entretanto, como alerta Zaffaroni nas palavras preliminares do livro de Camargo, "el riesgo es la perversión del discurso: lo punitivo no es solo lo que ejercen policías, jueces, fiscales, celadores y penitenciários, sino que se trata de um poder que siempre disputan corporaciones o categorías profesionales" (2005, p.14), incluindo-se, certamente, a dos psicólogos.
Por derradeiro, cabe mencionar que, no ano 2010, o CFP emitiu três resoluções que se referiam ao trabalho nessa área, ou seja, as Resoluções $n^{\circ}$ 008/2010, nº 009/2010 e $n^{\circ}$ 010/2010. A primeira veio dispor sobre a atuação do psicólogo como perito e assistente técnico no Poder Judiciário. A Resolução $n^{\circ}$ 009/2010 abrangia essa atuação no sistema prisional, vedando a esses profissionais a realização do exame criminológico. A Resolução n ${ }^{\circ}$ 10/2010 institui a regulamentação da Escuta Psicológica de Crianças e Adolescentes envolvidos em situação de violência, na Rede de Proteção, vedando ao psicólogo o papel de inquiridor daqueles que supostamente estariam nessa situação. Essa última resolução (CFP, 2010a) trata de demanda recentemente direcionada à categoria e que tem dividido opiniões e posicionamentos. O teor das discussões que sucederam a publicação dessas três resoluções, como expresso na carta divulgada pela Sociedade Brasileira de Psicologia (SPB, 2010) contra os posicionamentos adotados pelo CFP, demonstra que os impasses quanto ao encontro da Psicologia com o Direito - como já nomeava Verani em 1993 persistem, ou talvez continuem acentuados, como se expõe a seguir.

\section{Apontamentos sobre as práticas atuais}

Não se pode desconsiderar que, atualmente, muitas são as demandas que se enquadram na seara do Direito da infância e da juventude e do Direito de família direcionadas aos psicólogos. Mudanças rápidas e numerosas no formato das organizações familiares também são responsáveis por encaminhamentos até então pouco frequentes nos juízos, como as solicitações para o compartilhamento da guarda de filhos, as contestações de paternidade e os pedidos de adoção por cônjuge, dentre tantos outros. Observase que equipes interprofissionais foram 
integradas às Varas de Família, mantendose, de igual modo, o trabalho de assistentes técnicos e de peritos que não possuem vínculo empregatício com o Poder Judiciário. Com esse panorama, não se deve estranhar a demanda que deu origem à Resolução $n^{\circ}$ 008/2010, do CFP, que visa a estabelecer parâmetros ao exercício profissional de assistentes técnicos e peritos.

No que diz respeito ao trabalho desenvolvido pelas equipes que atuam junto aos Juízos de Família, como bem percebeu Miranda Júnior, há divergências em relação às práticas, destacando o autor três posicionamentos comumente adotados. Um grupo de profissionais defende a realização de práticas periciais pelos que compõem essas equipes; um segundo grupo, contrário a esse posicionamento, considera que a atuação deve "pautar-se pela escuta da singularidade e pela intervenção na dinâmica familiar", e uma terceira posição seria a dos que "oscilam entre os dois primeiros" (2010, p. 23). Pode-se recordar, por exemplo, que Costa, Penso, Legani e Sudbrack defendem, nesse contexto, a realização de um estudo psicossocial no lugar da perícia, interpretando que este facilitaria também a adoção de uma "dimensão interventiva" (2009, p. 236) no trabalho realizado, noção que se aproxima daquela do segundo grupo citado por Miranda Júnior.

No contexto contemporâneo, notase também que novas questões, com denominações até então desconhecidas, são encaminhadas ao Poder Judiciário e, portanto, aos psicólogos, sob justificativas de proteção de direitos e de segurança. Abandono afetivo, assédio moral, bullying, burnout, são exemplos de temas que têm gerado pesquisas, interrogações e debates, pois requerem constantes indagações além de um olhar crítico para os desdobramentos de possíveis intervenções. Percebe-se, ainda, o clamor popular por políticas penais mais severas, além da busca de penalizações para maior número de situações e de comportamentos.

O somatório dessas questões talvez contribua para o que Arantes percebeu como "certo mal-estar existente entre os psicólogos que atuam no âmbito Judiciário", que remete à indagação de "como pensar a relação entre Psicologia e Direito" (2008, p.131). Na visão dessa pesquisadora, a ampliação e a diversidade das demandas encaminhadas aos que atuam na interface com a Justiça remetem ao que classifica como um "novo mal-estar" (2008, p.133) entre os profissionais, não o mal-estar que inicialmente se instalou e que dividia a categoria a respeito das práticas a serem empreendidas nesse âmbito, mas o mal-estar que deriva de uma perceptível e crescente interferência "de parte do Poder Judiciário" no que seriam decisões da categoria dos psicólogos, que incluem a determinação de atividades, dos procedimentos e dos limites éticos da atuação. No campo da Justiça da infância e da juventude, encontra-se exemplo desse malestar na prática denominada Depoimento sem Dano (Daltoé Cezar, 2007), procedimento que surgiu em Porto Alegre (RS) e que passou a ser utilizado em diversas localidades, visando a obter o depoimento judicial de crianças e de adolescentes que supostamente sofreram abuso sexual. A indicação para que psicólogos e assistentes sociais se incumbam dessa prática transmitindo aos pequenos as perguntas formuladas pelo juízo, ao mesmo tempo em que é defendida por alguns (Tabajaski, 2009), vem gerando constantes indagações e contrariedades (Brito, 2012), havendo aqueles que, como Arantes (2008), não a identificam como uma "prática psi". A efervescência desse debate resultou na publicação, pelo CFP, da Resolução $\mathrm{n}^{\circ}$ 010/2010, que se propôs regulamentar a escuta psicológica de crianças e adolescentes envolvidos em situação de violência, na Rede de Proteção. 
Ainda no campo da infância e da juventude, pode-se pontuar que não são apenas as denominadas novas demandas e as suas implicações no trabalho a ser desenvolvido por psicólogos que vêm sendo debatidas. Na inspeção nacional às unidades de internação de adolescentes em conflito com a lei (CFP, 2006), realizada por meio de uma parceria do Conselho Federal de Psicologia e do Conselho Federal da Ordem dos Advogados do Brasil, foram evidenciadas as degradantes condições em que eram mantidos adolescentes em unidades de internação de diversos Estados brasileiros. Em nove de abril de 2012, matéria divulgada em jornal de grande circulação (Otavio, 2012) apresenta informações sobre pesquisa na qual o Conselho Nacional de Justiça levantou as condições a que são submetidos jovens em conflito com a lei em 320 unidades de internação do País, constatando que a situação mais grave, com superlotação das unidades, agressões e falta de atividades, ocorre em Estados da Região Nordeste. Dois dias antes, porém, foi a vez de o Estado do Espírito Santo estar no centro dos debates (Dalvi, 2012) com a divulgação de foto, feita em visita surpresa da Pastoral do Menor, que mostrava jovens algemados uns aos outros e presos a camas que dividiam na Unidade de Atendimento Inicial, em Vitória (ES).

Apesar de diversos direitos de crianças e de adolescentes dispostos no ECA não estarem sendo assegurados - como é de notório conhecimento - em pesquisa realizada recentemente em unidade de internação localizada no Maranhão, Sousa (2012) constatou que a tarefa principal dos que integram a equipe interprofissional que lá atua continua a ser a realização de avaliações periódicas dos adolescentes. Os critérios utilizados nas avaliações empreendidas pelos psicólogos não parecem distintos dos que foram anteriormente apontados por Violante (1984, p. 96), ou seja, a "adaptação conformada à realidade institucional" permanece equiparada à reabilitação dos jovens.

Na seara da execução penal, também sobressaem no noticiário as degradantes condições de algumas penitenciárias do País. O presídio central de Porto Alegre esteve no foco da imprensa em abril de 2012, quando foram amplamente divulgadas (Salinet, 2012) a superlotação e a falta de condições sanitárias para abrigar 4.650 detentos em unidade que deveria abrigar 1.850 internos. No que tange ao trabalho dos psicólogos na execução penal, embora a Lei $n^{\circ} 10.792$, de 2003, tenha alterado o artigo da LEP que previa a realização do chamado exame criminológico pela Comissão Técnica de Classificação anteriormente responsável por indicar se o detento estaria recuperado e em condições de merecer progressão de regime - persistem os pedidos para realização do exame. Por esse motivo, percebem-se embates em relação à pertinência de se mantê-lo, tanto entre os profissionais da Psicologia como entre os operadores do Direito. Dessa forma, a Resolução n 009/2010, do CFP, foi suspensa, visando a viabilizar a discussão a respeito de uma nova proposta para a atuação dos psicólogos junto ao sistema prisional. Buscando debater o tema, o Conselho Federal de Psicologia organizou, em São Paulo, em 19 e 20 de novembro de 2010, o Fórum Nacional Desafios para a Resolução sobre a Atuação do Psicólogo no Sistema Prisional. Na conferência de abertura do evento, Karam, juíza aposentada, esclarece que

A Lei $\mathrm{n}^{\circ}$ 10.792/2003, introduzindo novos dispositivos ao artigo 112 e seus $\S \S$ da Lei de Execução Penal, afastou desautorizadas previsões anteriores do 'exame criminológico', passando a exigir para a progressão da pena, além do decurso dos prazos cumpridos nos regimes mais rigorosos, unicamente o bom comportamento carcerário, comprovado pelo diretor do estabelecimento prisional. Surpreendentemente, porém, não afastou da viciada prática da Justiça criminal brasileira 
a indevida exigência daquele exame, já em si, inexigível (2010).

Em 10 de junho de 2011, a Resolução $n^{\circ}$ 012/2011 revogou a Resolução CFP $n^{\circ} 009 / 2010$, e passou a regulamentar a atuação de psicólogos no âmbito do sistema prisional.

\section{Considerações finais}

Como se tentou apontar ao longo deste ensaio, não se considera que a Psicologia jurídica seja uma nova área para os psicólogos, como alguns poderiam supor. As articulações da Psicologia com o Direito vêm de longe, além de terem contribuído com a criação dos primeiros laboratórios de Psicologia.

Nos últimos anos, avultam as demandas encaminhadas ao sistema de Justiça, e despontam novas e inúmeras possibilidades de atuação na área aqui denominada Psicologia jurídica. Não se pode perder de vista, porém, as incontáveis interrogações que precisam ser respondidas ao se iniciar qualquer trabalho nesse campo, o que provavelmente motivou o CFP a publicar diversas resoluções recentemente. No cenário que se descortina para esses profissionais no terceiro milênio, considerase que uma atitude de suspeita constante, de desconfiança, ou ainda o desenvolvimento de uma postura de investigação não soam como comportamentos a serem adotados por psicólogos jurídicos em seus atendimentos. Conclui-se, porém, que essa deveria ser uma rotina para com as solicitações encaminhadas aos psicólogos, favorecendo, assim, o que a Resolução n 007/2003 do CFP denomina "uma intervenção sobre a própria demanda" (2003, p. 4). Quiçá, a partir daí, tenha início a redução do mal-estar ao qual se refere Arantes, na medida em que o profissional talvez possa ter mais segurança das opções de trabalho que fará a partir das demandas que lhe foram direcionadas, optando por caminhos profissionais que não serão traçados ou indicados por outras disciplinas, mas construídos, com discernimento, conhecimento, certeza e ética pelo psicólogo.

Leila Maria Torraca de Brito

Professora Associada da Universidade do Estado do Rio de Janeiro. Doutora em Psicologia pela PUC/RJ - Rio de Janeiro - RJ - Brasil

E-mail: torraca@uerj.br ou leilatorrbrito@yahoo.com.br 


\section{Referências}

Anastasi, A. (1972). Campos da psicologia aplicada. São Paulo: Herder.

Arantes, E. M. M. (2008). Mediante quais práticas a psicologia e o direito pretendem discutir a relação? Anotações sobre o mal-estar. In C. Coimbra, L. Ayres \& M. L. Nascimento (Orgs.), Pivetes: encontro entre a psicologia e o judiciário (pp. 131-148). Curitiba: Juruá.

Barros, F. O. (2001). Do direito ao pai. Belo Horizonte: Del Rey.

Brasil. (1979). Lei $n^{\circ}$ 6.697, de 10 de outubro de 1979. Institui o Código de Menores. Brasília, DF: Autor.

Brasil. (1984). Lei $n^{\circ} 7210$, de 11 de julho de 1984. Institui a Lei de Execução Penal. Brasília, DF: Autor.

Brasil. (1990). Lei no 8.069, de 13 de julho de 1990. Institui o Estatuto da Criança e do Adolescente. Brasília, DF: Autor.

Bernardi, D. C. F. (1999). História da inserção do profissional psicólogo no tribunal de justiça do estado de São Paulo - um capítulo da psicologia jurídica no Brasil. In L. Brito (Org.), Temas de psicologia jurídica (pp.103-132). Rio de Janeiro: Relume Dumará.

Brito, L. M. T. (1993). Se-pa-ran-do: um estudo sobre a atuação do psicólogo nas Varas de Família. Rio de Janeiro: Relume-Dumará, UERJ.

Brito, L. M. T. (2012). Das avaliações técnicas aos depoimentos infantojuvenis: novos rumos dos casos de suspeita de abuso sexual. In L. Brito (Org.), Escuta de crianças e de adolescentes: reflexões, sentidos e práticas (pp.51-86). Rio de Janeiro: EdUERJ.

Coimbra, C. (2002). Os psicólogos e o labirinto, os psicólogos no labirinto? In Anais do encontro labirintos da demanda (pp.13-15). Rio de Janeiro: Programa de Formação em Direitos da Infância e da Juventude - UERJ/Divisão de Psicologia da 1ª Vara da Infância e da Juventude do Rio de Janeiro.

Conselho Federal de Psicologia. (2003). Resolução CFP n 007/2003. Institui o Manual de Elaboração de Documentos Escritos produzidos pelo psicólogo, decorrentes de avaliação psicológica, e revoga a Resolução CFP n 17/2002. Brasília, DF: Autor.

Conselho Federal de Psicologia. (2005). Resolução CFP $n^{\circ}$ 010/05. Aprova o Código de Ética Profissional do Psicólogo. Brasília, DF: Autor.

Conselho Federal de Psicologia. (2006). Inspeção nacional às unidades de internação de adolescentes em conflito com a lei. Brasília, DF: Autor.

Conselho Federal de Psicologia. (2010). Referências técnicas para atuação do psicólogo em Varas de Família. Brasília, DF: Autor.

Conselho Federal de Psicologia. (2010a). Resolução CFP n 10/2010. Recuperado em 10 julho, 2010, de http://www.pol.org.br/pol/ export/sites/default/pol/legislacao/legislacaoDocumentos/reso lucao2010_010.pdf.

Conte, B. (2006, maio/jun.). A ética na prática da avaliação psicológica. Revista Entrelinhas, 34, 5.

Costa, L. F. , Penso, M. A. , Legnani,V. N., \& Sudbrack, M. F. (2009). As competências da psicologia jurídica na avaliação psicossocial de famílias em conflito. Psicologia e Sociedade, 21(2), 233-241.

Daltoé Cezar, J. A. (2007). Depoimento sem dano: uma alternativa para inquirir crianças e adolescentes nos processos judiciais. Porto Alegre: Livraria do Advogado Editora.

Dalvi, B. (2012, 5 de abr.). Jovens dormiam algemados no Espírito Santo. O Globo, 13.

Jacó-Vilela, A. M. (1999a). Psicologia: um saber sem memória? In A. M. Jacó-Vilela , H. C. Rodrigues \& F. Jabur (Orgs.), Clio-Psyché - Histórias da Psicologia no Brasil (pp. 247-255). Rio de Janeiro: UERJ/NAPE

Jacó-Vilela, A. M. (1999b). Eliezer Schneider: um esboço biográfico. Estudos de Psicologia, 4(2), 331-350.

Karam, M. L. (2010). Relação histórica da psicologia com o sistema prisional. Recuperado em 07 março, 2012, de http://www. pol.org.br/pol/cms/permalink/95b7d5f3-f7d2-11df-9872db013ef28d65.pdf

Krüger, H. (2009). Hanns Ludwig Lippmann e o curso de psicologia da UERJ. In A. M. Jacó-Vilela (Org.), Psicologia na UERJ: 45 anos de histórias (pp. 13-30). Rio de Janeiro: EdUERJ.

Mira y López, E. (1967). Manual de psicologia jurídica (E. Arruda, trad.) São Paulo: Mestre Jou (Trabalho original publicado em 1945).

Miranda Júnior, H. C. (1998). Psicologia e justiça: a psicologia e as práticas judiciárias na construção do ideal de justiça. Psicologia: Ciência e Profissão, 18(1), 28-37.

Miranda Júnior, H.C. (2010). Um psicólogo no tribunal de família: a prática na interface direito e psicanálise. Belo Horizonte: Editora ArteSã.

Mures, N. F. (1983). Ética e desempenho profissional. In L. Brito (Org.), Psicologia e instituições de direito: a prática em questão (pp. 59-62). Rio de Janeiro: Comunicarte.

Otavio, C. (2012, 9 de abr.). Infratores pela segunda vez. O Globo, 3. Ramos, M., \& Shaine, S. (1994). A família em litígio. In M. Ramos (Org.), Casal e família como paciente (pp. 95-122). São Paulo: Escuta.

Rauter, C. (1989). Diagnóstico psicológico do criminoso: tecnologia do preconceito. Revista de Psicologia da Universidade Federal Fluminense, 9-22.

Salinet, R. (2012). Presídio central de Porto Alegre vive seu pior momento, afirma juiz. Recuperado em 20 abril, 2102, de http:// g1.globo.com/rs/rio-grande-do-sul/noticia/2012/04/presidiocentral-de-porto-alegre-vive-seu-pior-momento-afirma-juiz.html

Saunier, R. (1999). Desafios de la psicología forense ante el nuevo milenio. In Anais do III Congresso Iberoamericano de Psicologia Jurídica, (pp.319-324). São Paulo: Associação Brasileira de Psicologia Jurídica/Asociación Iberoamericana de Psicología Jurídica. Recuperado em 20 março, 2009, de www.bvs-psi.org. $\mathrm{br} /$ local/file/congressos/AnaisPgsIntrod-artel.pdf.

Sociedade Brasileira de Psicologia. (2010). Sociedades científicas brasileiras contra as Resoluções do Conselho Federal de Psicologia. Recuperado em 12 novembro, 2010, de http://www.sbponline. org.br/noticiasinterna.php?id=88.

Sousa, F. J. (2012). Medida socioeducativa de internação no Maranhão: uma visão de seus atores. Tese de doutorado. Instituto de Psicologia, Universidade do Estado do Rio de Janeiro, Rio de Janeiro, RJ.

Tabajaski, B. (2009). O depoimento especial de crianças/adolescentes vítimas de violência: um encontro entre direitos humanos, o saber jurídico e a ciência psicológica. In B. M. Paulo (Org.), Psicologia na prática jurídica: a criança em foco (pp. 289-302). Niterói, RJ: Impetus.

Teixeira, M. F. (1993). Criação do cargo de psicólogo no poder judiciário: uma luta necessária. In L. Brito (Org.), Psicologia e instituições de direito: a prática em questão (pp. 55-58). Rio de Janeiro: Comunicarte.

Teixeira, M. F., \& Belém, R. C. (1999). Breve relato sobre a implantação de um serviço de psicologia jurídica. In L. Brito (Org.), Temas de psicologia jurídica (pp. 59-72). Rio de Janeiro: Relume Dumará.

Verani, S. (1993). Alianças para liberdade. In L. Brito (Org.), Psicologia e instituições de direito: a prática em questão (pp. 14-20). Rio de Janeiro: Comunicarte.

Violante, M. L. V. (1984). O dilema do decente malandro. São Paulo: Cortez.

Urra Portillo, J. (2010). Critérios éticos para psicólogos jurídicos. Anuário de psicologia Jurídica, 20, 93-104.

Zaffaroni, R. (2005). Palabras preliminares. In L. Camargo, Encrucijadas del campo psi-jurídico (pp.13-15). Buenos Aires: Letra Viva. 